\title{
From Proteinuria to Fibrosis: An Update on Pathophysiology and Treatment Options
}

\author{
Sonia Sharma ${ }^{a}$ Brendan Smyth ${ }^{b}$

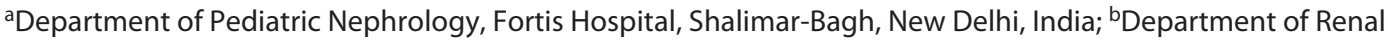 \\ Medicine, St. George Hospital, Sydney, NSW, Australia
}

\section{Keywords}

Proteinuria $\cdot$ Renal physiology $\cdot$ Kidney fibrosis .

Albuminuria $\cdot$ Chronic kidney disease

\begin{abstract}
Background: Proteinuria is a key biomarker in nephrology. It is central to diagnosis and risk assessment and the primary target of many important therapies. Etiologies resulting in pathological proteinuria include congenital and acquired disorders, as well as both glomerular (immune/non-immune mediated) and tubular defects. Summary: Untreated proteinuria is strongly linked to progressive loss of kidney function and kidney failure. Excess protein reaching the renal tubules is ordinarily resorbed by the tubular epithelium. However, when these mechanisms are overwhelmed, a variety of inflammatory and fibrotic pathways are activated, causing both interstitial fibrosis and glomerulosclerosis. Nevertheless, the specific mechanisms underlying this are complex and remain incompletely understood. Recently, a number of treatments, in addition to angiotensin system blockade, have been shown to effectively slow the progression of proteinuric chronic kidney disease. However, additional therapies are clearly needed. Key message: This review provides
\end{abstract}

karger@karger.com www.karger.com/kbr

Karger!
C 2021 The Author(s).

Published by S. Karger AG, Basel

This is an Open Access article licensed under the Creative Commons Attribution-NonCommercial-4.0 International License (CC BY-NC) (http://www.karger.com/Services/OpenAccessLicense), applicable to the online version of the article only. Usage and distribution for commercial purposes requires written permission. an update on the pathophysiology of proteinuria, the pathways leading to fibrosis, and an overview of current and emerging therapies.

(C) 2021 The Author(s)

Published by S. Karger AG, Basel

\section{Introduction}

Proteinuria plays a critical role in the diagnosis and management of both primary and secondary renal diseases $[1,2]$. The significance of proteinuria was first glimpsed when Hippocrates described frothy urine as a marker of kidney disease in 400 B.C., and a coagulated material (protein) in urine was observed from the 16th century, but it was not until the early 19th century that Bright linked this specifically to kidney disease [3, 4]. It was only in the mid-20th century that simple tests became available for the easy detection of proteinuria [5]. Proteinuria, and its treatment, is now at the cutting edge of recent progress in the management of kidney disease, both as one of the 2 central biomarkers (with serum creatinine) in nephrology and as treatment targets for inhibitors of the renin-angiotensin system and, more re- 
cently, sodium-glucose transporter 2 inhibitors (SGLT2i) - which appear to represent an important leap forward in the care of patients with chronic kidney disease $(\mathrm{CKD})[6,7]$.

\section{The Physiology and Pathophysiology of Proteinuria}

To prevent the loss of serum proteins during the filtration process, the kidney relies on the complex structure of the glomerular filtration barrier (GFB), supplemented by reuptake of filtered protein by the renal tubules. Healthy kidneys receive approximately 1,200 mL blood per minute, equating to $625 \mathrm{~mL}$ per minute of plasma reaching the glomerular capillaries. Twenty per cent of this plasma crosses the filtration barrier (hence, the normal glomerular filtration rate [GFR] $125 \mathrm{~mL} / \mathrm{min}$ ) and enters the renal tubules. In the absence of a filtration barrier, this would result in around $26 \mathrm{~g}$ of albumin reaching the renal tubules per minute, yet albumin excretion in a healthy individual is $<30 \mathrm{mg}$ per day. Thus, healthy human kidneys are $>99.9999 \%$ effective at preventing albumin loss. Indeed, the majority of the $<150 \mathrm{mg}$ per day of protein found in normal urine is not filtered from plasma but originates from renal tubular cells in the thick ascending limb of the loop of Henle. The function of this TammHorsfall protein (or uromodulin) is not well understood, with possible roles being to activate sodium uptake in distal tubular cells or to inhibit calcium stone formation [8].

The key structure in the prevention of proteinuria is the GFB. The GFB comprises 3 distinct layers: endothelium, basement membrane, and podocytes [9]. The primary determinants of filtration across the barrier are size and charge, with larger and negatively charged molecules being selectively prevented from crossing (perm selectivity) [10]. The first layer is composed of endothelial cells which allow movement of large volumes of fluid via pores called fenestrae. At 60-100 nm in width, the fenestrae are larger than albumin, but the movement of anionic macromolecules is limited by the presence of a negatively charged surface coating, known as the glycocalyx (up to $300-\mathrm{nm}$ thick) consisting of proteoglycans, glycosaminoglycans, and trapped plasma proteins such as orosomucoids. A more recent (although debated) hypothesis holds that an important contributor to the negative charge limiting plasma protein movement across the GFB is a "streaming potential" $[11,12]$. This term describes a potential difference established by the continuous flow across the GFB which, owing to the anionic character of the glycocalyx and glomerular basement membrane
(GBM), favours cations. The flow of solute becomes electrically unbalanced, resulting in the build-up of anions on the interior edge of the GFB. It is possible that this, rather than the glycocalyx, is primarily responsible for preventing albumin migrating through the fenestrae of the glomerular endothelium. Underlying the endothelial cells is the GBM, an intertwined network of fibrils built of type IV collagen and laminins, with over 100 other proteins, including nidogen (entactin) and heparan sulphate proteoglycans (e.g., perlecan, agrin, and collagen XVIII) [13]. The protein components are highly hydrated leading to a gel-like structure, with spaces between the fibrils averaging $10 \mathrm{~nm}$ in diameter. It provides the critical size barrier and may contribute to repulsion of negatively charged macromolecules. Finally, supporting the GBM are podocytes, highly specialized visceral epithelial cells with interlocking projections known as foot process. The space between foot processes is bridged by a porous intercellular junction known as the slit diaphragm [14]. It restricts proteins of size $>60 \mathrm{~A}^{0}$ and provides negative charge repulsion (with a sieving coefficient $\sim 0.02-0.06$ ).

Theories of GFB function emphasize the importance of podocytes for basement membrane function. In the healthy glomerulus, the support provided by the podocyte foot processes ensures that the pressure exerted on the basement membrane by the flow of filtered fluid causes compression of the gel-like basement membrane structure, crowding the protein matrix together, such that the space available for transit is minimized. Without effective podocyte support, the pressure of filtration flow causes the basement membrane to stretch longitudinally (imagine a rubber band being widened), such that the space available for transit is increased, leading to proteinuria. Understanding of podocyte function has been greatly enhanced by the study of the numerous genetic mutations resulting in steroid resistant nephrotic syndrome in childhood. The 2 earliest identified genes recognized both code for proteins forming part of the structure of the podocyte and slit diaphragm actin-cytoskeleton-nephrin (NPHS1) and podocin (NPHS2), with many others since described (Table 1). These podocytopathies result in effacement of the foot processes and failure of the GFB. Finally, it is now known that primary GBM disorders can result in podocytopathy, as shown in Alport's disease, where a deficiency in type 4 collagen (a key constituent of the GBM) leads to thinned GBM and which has recently been shown to also result in podocyte foot process effacement and podocyte loss [15]. Overall, this emphasizes that the function of each component of the GFB is dependent on the health of the other constituent parts. 
Table 1. Podocytopathy and proteinuria

Podocyte genes mutations defects

Slit membrane genes

NPHS1 (AR): premature birth and enlarged placenta

NPHS2 (AR), PLCE1, and CD2 AP

TRPC6 (AD, late onset proteinuria), PTPRO (AR), CRB2, and FAT1

Nuclear genes

WT1 (AD, sporadic with affected genitalia; Wilms' tumour, Denys-Drash, and Frasier syndromes), LMX 1B (AR, dystrophic nails, and patellar hypoplasia/aplasia), SMARCAL1 (AR, Schimke immuno-osseous dysplasia which is characterized by growth failure and immune deficiency), E2F3 (deletion), NSX5 (X-linked), PAX2 (AD), WDR 73 (AR and Galloway-Mowat syndrome having microcephaly with brain anomalies), NUP $(93,85,107,133,205)$, and XPO5 (AR)

Actin cytoskeleton signalling ACTN4 (AD) and MYH9 (Allele)

INF2 (AD) peripheral neuropathy and FSGS, SYNPO, APOL 1 (AR), MYO1E (AR), ARHGAP24 (familial AD SRNS in late 2nd and 3rd decade), ARHGDIA (AR with neurological abnormalities), ANLN (AD), EMP2 (AR), CUBN (AR), GPC5 (Allele),

PODXL (AD), TTC21B (AR), CLTA4 (Allele), PLCE, ITSN 1\& 2, KANK 1,2, and 4, MAGI2, and TSN2

Mitochondrial

MTTL1 (MELAS syndrome), tRNA1le (deafness, heart, and epilepsy), COQ6 (deafness), COQ2, COQ8B, PDSS2, ADCK4, and CYP11B2

Lysosomal/metabolic

PMM2 (AR), ALG1 (AR), and SCARB2 (AR)

Acquired causes

Diabetes, obesity, and hypertension

Hypoplasia, agenesis, and reflux nephropathy

Cyanotic heart diseases

Immune complex glomerulonephritis

Metabolic storage disorders

Monoclonal gammopathies and amyloidosis

Glomerular basement membrane defects

Alport syndrome ( $\alpha 1-\alpha 5$ chain of type IV collagen) with sensorineural deafness and thin basement membrane disease ( $\alpha 4$ chain mutation)

Pierson's syndrome (LAMB2 gene) with ocular abnormalities

Mutations in ITGA3 (integrin $\alpha 3$ ) and ITGB4 ( $\beta 4$ ) causes congenital nephrotic syndrome with epidermolysis bullosa

Good-pasture syndrome (antibodies against type IV a3 chain)

\section{Causes of Glomerular Proteinuria}

An enormous variety of acquired glomerular pathologies result in proteinuria. These can be autoimmune diseases, inflammatory disorders, infiltrative or metabolic diseases, hypertension, toxins, and systemic infections [16]. The spectrum of presentation of glomerulonephritis, with its 2 poles of nephrotic and nephritic syndrome is, in large part, determined by the degree of proteinuria. Generally speaking, these presentations reflect the underlying histopathology. Nephrotic syndromes are characterized by more specific disruption (whether by immune or non-immune pathology) of the GFB, such as the immune complex deposition within the GBM in membranous nephropathy or the widespread foot process effacement and podocytopathy seen in minimal change or focal segmental glomerulosclerosis. Nephritic syn- dromes, such as vasculitis or IgA disease, are characterized more by cellular infiltration or proliferation of mesangial cells and destruction of the glomerulus as a whole. With more generalized destruction of the filtration capacity of individual nephrons, there is less opportunity for massive proteinuria and the nephrotic syndrome. Among acquired aetiologies of CKD, diabetes is of special importance. Glomerular hyperfiltration is the first stage of diabetic kidney disease. Although exact underlying mechanism is still not known, a role is hypothesized for proximal tubular reabsorption of excess glucose via SGLT2 and associated reduced distal delivery of sodium [17]. Reduced luminal sodium then subsequently lessens tubulo-glomerular feedback, causing dilatation of afferent arterioles and angiotensin-induced constriction of efferent arterioles and therefore hyperfiltration. Other factors which assist this mechanism in diabetic kidney 
disease include hyperaminoacidemia, hypertension, and obesity.

\section{Tubular Reabsorption of Filtered Protein and Tubular Proteinuria}

While the GFB is unable to prevent filtration of lowmolecular weight (LMW) $(<30 \AA$ and $<40,000$ D) proteins which then enter the lumen of the renal tubule; the renal tubule is able to resorb $95 \%$ of these filtered proteins, along with the tiny fraction of larger proteins (including albumin) which have escaped the GFB $[18,19]$. The bulk ( $70 \%)$ of the reabsorption occurs in the proximal tubules via apical endocytic receptors, megalin, and cubilin, which bind luminal protein. The protein-receptor complexes are then clustered into clathrin-coated pits and further endocytosed and undergo final processing within lysosomes [20, 21]. Additionally, fluid-phase (clathrin-negative) neonatal Fc receptor-mediated transcytosis also has a role in resorption of albumin [22]. Endocytosed protein in the lysosomes is hydrolyzed to amino acids and ultimately returned into the circulation via the basolateral membrane $[23,24]$. Dysfunction of the proximal tubular epithelium thus results in "tubular proteinuria" characterized by the presence of LMW proteins such as beta 2 microglobulin and alpha 1 microglobulin in the urine in amounts disproportionate to albumin (indicating that the GFB is largely intact). Congenital tubulopathies resulting in proximal tubular dysfunction and other secondary causes of Fanconi syndrome as systemic diseases, drugs, and toxins result in tubular proteinuria. Mutations of CUBN (encoding cubulin) and AMN (a gene encoding a transmembrane protein important for megalin stability) result in Imerslund-Gräsbeck syndrome, defined by tubular proteinuria and megaloblastic anaemia due to cobalamin deficiency (reflecting the role of these proteins in the gastrointestinal system uptake of cobalamin) [25]. Persistence of tubular proteinuria of any cause can, over a long period of time, result in interstitial tissue fibrosis and reduced kidney function.

\section{Other Causes of Proteinuria}

Overflow proteinuria results from an excess of LMW proteins in the serum, owing to systemic illness. This protein is filtered at the glomerulus but exceeds the resorptive capacity of the tubular epithelium. The most common example is light chains from myeloma, but other examples include myoglobinuria from rhabdomyolysis or haemoglobinuria from paroxysmal nocturnal haemoglobinuria or other causes of intravascular haemolysis. Functional proteinuria is the benign and transient appearance of proteinuria, following exertion due to exercise, fever, heart failure, or other hyperadrenergic states. The mechanism is thought to relate to transient increased glomerular pressure or flow but is not well understood. Orthostatic proteinuria is proteinuria seen in children and young adults and which is only present when the individual has been upright. The explanation is unclear, but one recent hypothesis proposes that the fall in blood pressure and renal plasma flow when upright leads to a diminished streaming potential across the GFB. Hence, with less negative charge build up on the blood-side, albumin can more easily pass across the fenestrated glomerular endothelium [26]. Orthostatic proteinuria, although sometimes associated with the nutcracker phenomenon, is typically benign and does not lead to progressive loss of kidney function.

\section{Proteinuria and Progressive Kidney Disease}

The importance of proteinuria lies, primarily, in its association with progressive loss of kidney function and eventual kidney failure. Moreover, changes in proteinuria are correlated strongly with kidney outcomes. For example, in a large population cohort, a 4 -fold increase in albuminuria associated with a 3 -fold increase in risk of subsequent kidney failure was compared to individuals with stable albuminuria, while a 4 -fold decrease in albuminuria was associated with only one-third the risk of kidney failure. [27] Worse prognosis with increasing proteinuria is seen in virtually all kidney diseases, including diabetes and non-diabetic CKD, and in paediatric populations [28]. Apart from renal progression, proteinuria also correlates strongly with cardiovascular morbidity and mortality, stroke, and diabetic vascular complications. These associations are, in part, reflective of more severe underlying kidney disease or more severe systemic disease driving kidney pathology (e.g., diabetes). However, it is also clear that proteinuria itself drives the pathophysiological process of worsening kidney function and directly influences cardiovascular risk.

The pathophysiology linking proteinuria to loss of kidney function is complex and still incompletely understood, but a detailed picture is emerging which centres on the tubular epithelial cell response to filtered protein. Filtered albumin is reabsorbed by proximal tubular epithe- 
lial cells as described above. However, with heavy or persistent proteinuria, intracellular pathways involving lysozymes and the endoplasmic reticulum, designed to handle reabsorbed albumin, are stressed or overwhelmed [29]. Tubular cells respond by the production of cytokines, encouraging inflammation, and attracting inflammatory cells, such as macrophages [30]. Albumin also induces a range of changes in tubular cell function that may culminate in apoptosis [31]. Also, albumin-bound free fatty acid (especially oleic/linoleic acid) and metabolites of non-essential fatty acid long-chain acyl-CoA stimulate lipoapoptosis of tubular cells [32]. More generally, the changes in stressed renal tubular cells represent a shift towards a partial mesenchymal phenotype, which includes the production of profibrotic mediators such as transforming growth factor-beta 1 (TGF- $\beta 1$ ) [33]. A minority of renal tubular cells take this transition further and migrate to the interstitium where, along with existing interstitial fibroblasts, they contribute directly to the production of extracellular matrix and fibrosis. Albumin exposure also directly, via an epigenetic mechanism, reduces Klotho expression in proximal tubular cells, which is believed to contribute to hyperphosphataemia, higher levels of fibroblast growth factor-23, and lower levels of circulating Klotho $[34,35]$. This may, in part, explain the importance of albuminuria as a cardiovascular risk factor; a link demonstrated by the finding that, independent of changes in other biomarkers, albuminuria lowering explained $36 \%$ of the beneficial effect of canagliflozin on cardiovascular events [36].

Our understanding of the signalling pathways involved in the response of the renal tubular epithelium to proteinuria and the development of fibrosis is constantly growing. A wide range of involved cytokines, microRNA, and extracellular vesicles is now known to transmit information, either between cells within the tubular epithelium or between the epithelium and interstitium [37]. Pathways activated in the presence of proteinuria include those involving TGF- $\beta / S M A D$, protein kinase $C$ and mitogen-activated kinase, angiotensin II, c-Jun amino-terminal kinase, and Janus kinase/signal transducers and activators of transcription $[38,39]$. The activation of these pathways results in production of vasoactive, inflammatory, and profibrotic cytokines, including TGF- $\beta 1$, vasoconstrictor peptide endothelin-1, monocyte chemoattractant protein-1, tumour necrosis factor- $\alpha$, regulated upon activation normal $\mathrm{T}$ cell expressed and secreted, interleukin-8, interleukin-6, and fractalkine [40]. These then cause renal tubular epithelial cell proliferation, extracellular matrix deposition, and further attract more neutrophils, lymphocytes, monocytes, blood-sidemacrophages, myofibroblasts, and T cells. This cycle of inflammation and activated cellular response continues with further proliferation and dedifferentiation of renal epithelial cells towards a mesenchymal phenotype, progressive tubular damage and apoptosis, and eventual irreversible interstitial fibrosis. Interestingly, tubular damage due to proteinuria may itself lead to further glomerular pathology, with the potential for an adverse pathological cycle. Selective tubular injury has been observed to result in the subsequent development of glomerulosclerosis and proteinuria [41, 42]. Proposed mechanisms include tubular production of metalloproteases which cleave nephrin and result in podocyte foot process effacement but are not well understood [43-46]. The role of tubule-glomerular crosstalk in worsening kidney disease initiated by glomerular pathology mains to be further explored.

\section{Laboratory Aspects of Proteinuria}

Proteinuria should not exceed $150 \mathrm{mg}$ per day in a healthy individual. Other ways to define normal protein excretion include total proteins $<4 \mathrm{mg} / \mathrm{m}^{2} / \mathrm{h}$, albumin $<10-15 \mathrm{mg} /$ day, transferrin $<200 \mathrm{mg} / \mathrm{L}, \mathrm{IgG}<500 \mathrm{mg} / \mathrm{L}$, and beta- 2 microglobulin is $<600 \mathrm{mg} / \mathrm{L}$. In the presence of significant glomerular pathology, loss of $>3.5$ g per day per $1.73 \mathrm{~m}^{2}$ ( $1 \mathrm{~g}$ per day in children) defines nephrotic range proteinuria. For a spot urine test, an albumin-tocreatinine ratio above $220 \mathrm{mg} / \mathrm{mmol}$ (or protein-to-creatinine ratio above $350 \mathrm{mg} / \mathrm{mmol}$ ) is indicative of nephrotic range proteinuria in adults [47]. In children, a urine protein-to-creatinine ratio $>226 \mathrm{mg} / \mathrm{mmol}(2,000$ $\mathrm{mg} / \mathrm{g}$ ) is suggestive of nephrotic range proteinuria. It should be noted that the relationship between spot urine albumin or the protein-to-creatinine ratio and $24 \mathrm{~h}$ collected values is approximate, with the latter remaining the gold-standard measurement of proteinuria. Nevertheless, spot urine collections are far less cumbersome and are sufficiently reliable to be used for diagnosis and treatment initiation in the appropriate clinical context.

Laboratory measurement of proteinuria: Historically, heat coagulation and sulphosalicylic acid method were used to indicate the presence of proteinuria. Methods in current use include the urine reagent strip (which relies on a strip impregnated with tetrabromophenol blue, a $\mathrm{pH}$ indicator which changes colour in the presence of albumin), which detects predominantly albumin and is less sensitive to globulins and other LMW proteins. It is also easily altered with the dilution or contamination of the 
urine with genital secretions or haematuria. Turbidimetry measures the amount of total protein in a urine sample following the addition of a protein precipitant (e.g., trichloracetic acid, benzethonium chloride, or ammonium chloride), allowing the turbidity produced by small particles of denatured protein in suspension to be quantified. In this, there is an echo of the physicians of the early modern era adding vinegar to urine and observing the precipitate. Colorimetric methods rely on protein-binding dyes being added to the sample, and the resulting colour change being quantified. Nephelometry is the measurement of laser light scattered by antigen-antibody complexes suspended in a fluid. By adding anti-albumin antibodies to urine, nephelometry can be used to reliably measure the urine albumin concentration, including down to the microalbuminuria range.

\section{Treatment of Proteinuria}

Treatment of proteinuria is usually aimed at preserving kidney function in the medium to long term, as reducing the amount of proteinuria rarely has any short-term benefit for patients who are typically asymptomatic. Like blood pressure or serum cholesterol with respect to cardiovascular disease, proteinuria is a surrogate end point for kidney failure. Meta-analysis of 41 interventional studies has shown that every $30 \%$ reduction geometric mean albuminuria corresponds to an approximately equivalent reduction in the risk of kidney failure or doubling serum creatinine [48]. Individual patient metaanalysis of observational studies shows, similarly, an approximate $20 \%$ reduction in risk of kidney failure with a $30 \%$ reduction in proteinuria [49]. Initial management of both immune and non-immune-mediated proteinuric kidney disease primarily includes management of underlying aetiologies. But, refractory disease pathology with persistent proteinuria is common, leading to an ongoing need for effective antiproteinuric agents. The discovery of the antiproteinuric and nephroprotective effect of angiotensin-converting enzyme inhibitors (ACE inhibitors) and receptor blockers is a key milestone in nephrology, only recently matched by the success of SGLT2i.

Despite the importance of proteinuria as a surrogate for kidney outcomes, it is important to add that reduction in proteinuria does not always translate into preservation of kidney function and that conversely, reduction in proteinuria may, for some agents, not be necessary for preservation of kidney function. In the former category, the direct renin-inhibitor aliskiren, despite clear improve- ments in albuminuria, did not improve kidney or cardiovascular outcomes [50]. In the latter category, kidney outcomes were similarly improved in diabetic patients who did and did not experience at least a $30 \%$ improvement in albuminuria with atrasentan [51]. Clearly, mechanism of action and the disease affecting the cohort being studied matter. Recognizing this, expert and regulatory agency recommendations consider decline in eGFR over time ("eGFR slope") and sustained rises in serum creatinine ( $>40$ or $>50 \%$ ) to be more reliable surrogate end points for kidney failure than change in albuminuria [52]. Nevertheless, given its ease of measurement, and central importance to the pathophysiology of many kidney diseases, especially diabetic kidney disease and glomerulonephritis, reduction in proteinuria will remain a key treatment goal in nephrology $[53,54]$.

\section{ACE Inhibitors and Angiotensin II Antagonists}

Both agents effectively reduce urine protein loss in proteinuric CKD of any cause. Their primary action is well known, by blocking or reducing the effect of angiotensin II on the efferent glomerular arteriole, and they result in efferent arteriolar vasodilation and consequently lower intraglomerular pressure, resulting in a reduction in the flow across the GFB [55]. In addition, other mechanisms have been demonstrated, such as a reduction in the size of large unselective pores in the GBM and change in charge selectivity of the glomerular endothelium [56]. Beneficial effects on the mesangial cells have also been noted, with reduction in TGF- $\beta$ expression and mesangial matrix production, particularly in IgA nephropathy [57]. While these agents are effective, they can be challenging to use in patients who already have advanced kidney disease (eGFR $<30 \mathrm{~mL} / \mathrm{min} / 1.73 \mathrm{~m}^{2}$ ) due to the additional lowering of GFR and increased risk of hyperkalaemia. Nevertheless, these agents slow progression of both diabetic and proteinuric non-diabetic kidney diseases and have similar efficacy regardless of race [58-61]. Despite a lower certainty of benefit in those with $<0.5 \mathrm{~g} /$ day proteinuria [62], these agents remain the first-line therapy in adults as well as in children with proteinuric CKD [63]. Finally, it is now well-established that the combination of ACE inhibitors and angiotensin receptor blockers provides no renal benefit in patients at high cardiovascular risk with or without albuminuria and increases the risk of hyperkalaemia and acute kidney injury, despite further lowering of albuminuria [64-66]. Similar findings were noted with direct renin inhibitor, aliskiren [67]. 


\section{SGLT2 Inhibitors}

Beginning with the EMPA-REG OUTCOME trial of empagliflozin in patients with diabetes and elevated risk of cardiovascular disease in 2016, which showed a $39 \%$ reduction in risk of incident or worsening diabetic kidney disease, SGLT2i has emerged as a powerful addition to angiotensin system inhibitors in the treatment of proteinuric CKD $[68,69]$. Further studies have now emphatically confirmed these initial findings. The CREDENCE trial, which enrolled participants with macroalbuminuric diabetic kidney disease and showed a 30\% reduction in risk of progression to kidney failure, as well as a reduction in the rate of decline in kidney function with randomization to canagliflozin and DAPA-CKD, which enrolled a population of patients with proteinuric CKD of whom onethird did not have diabetes, showed a $44 \%$ reduction in risk of progression of kidney disease with dapagliflozin [70-73]. Meta-analysis of 6 studies including 46,969 participants with type 2 diabetes has found SGLT2i reduces adverse kidney outcomes by $38 \%$, along with a $10 \%$ reduction in risk of major adverse cardiovascular events and a $32 \%$ lower risk of hospitalized heart failure [74]. The primary mechanism underlying the effect of these agents is, like angiotensin system inhibitors, a reduction in intraglomerular pressure. This results from blockade of glucose uptake via SGLT2 in the proximal tubule, which leads to increased sodium and glucose reaching the distal tubule. At the macula densa, the increased sodium triggers tubuloglomerular feedback, causing afferent glomerular arteriolar constriction and so reduces intraglomerular pressure and ameliorates the hyperfiltration commonly seen in diabetic and other forms of CKD [75-80]. Multiple other pathways may also contribute to the beneficial effects of these agents, including moderate improvements in blood pressure and glycaemic control, increased haematocrit resulting in increased oxygen delivery to renal tissue, along with reductions in proinflammatory and profibrotic cytokines, and reduced oxidative stress [81]. Indeed, analysis of the CREDENCE and CANVAS trials suggests that albuminuria lowering explains between 42 and $48 \%$ of the overall effect of SGLT2i on kidney outcomes at least in patients with microalbuminuria, but only $7 \%$ of the effect in participants with normoalbuminuria $[36,82]$. Albuminuria-independent pathways are presumed to be responsible for the ability of SGLT2is to reduce decline in kidney function, even among people with diabetes and no albuminuria, although the absolute benefits on kidney outcomes are smaller, given the lower absolute risk in this cohort $[83,84]$.

From Proteinuria to Fibrosis

\section{Other Agents}

Many additional agents are being investigated for their potential to preserve kidney function in people with proteinuric CKD. Researchers are considering not only agents that reduce proteinuria directly, but also there is great interest in molecules to slow or prevent renal fibrosis. Various pathways are being considered. Two promising avenues presently appear to be endothelin antagonism and inhibition of mineralocorticoid receptors. In the SONAR study, the endothelin A antagonist, atrasentan, resulted in a 35\% reduction in adverse kidney events in 2,648 participants with diabetic kidney disease who had been seen to have an antiproteinuric response to atrasentan during an initial enrichment period $[85,86]$. Further studies are ongoing, including with other agents in this class and in patients with chronic glomerulonephritis. Most recently, finerenone, a non-steroidal mineralocorticoid receptor antagonist showed an $18 \%$ reduction in progression of kidney disease in 5,734 patients with diabetic kidney disease [87].

Treatments aiming to reduce or ameliorate the effects of oxidative stress include bardoxolone methyl, which was found ineffective and increased the risk of heart failure in a phase 3 study and selonsertib, a kinase inhibitor targeted to the apoptosis signal-regulating kinase 1 which has shown promise in an early phase study and for which further studies are underway $[88,89]$. Much interest has focused on TGF- $\beta$ and kidney fibrosis, however, to date, little success has been demonstrated. In a randomized study of 416 participants with diabetic kidney disease, an anti-TGF $\beta 1$ monoclonal antibody did not slow decline in kidney function [90]. Multiple studies are underway to further explore the potential of pirfenidone, an inhibitor of TGF- $\beta$-mediated fibrosis, which has shown some promise in small studies [91, 92].

\section{Conclusions}

Proteinuria is more than just a useful diagnostic indicator of kidney disease but also has a strong and consistent association with progression of CKD and with both renal and cardiovascular morbidity. In addition to angiotensin inhibitors, recent studies have clearly established the beneficial effects for SGLT2is and point to a role for endothelin receptor and mineralocorticoid receptor antagonists in preserving kidney function and preventing the need for renal replacement therapy. This success should stimulate further work to deepen our understand-

Kidney Blood Press Res 2021;46:411-420

417 
ing of the mechanisms linking proteinuria to progression of kidney disease, so as to identify additional future targets for therapy.

\section{Conflict of Interest Statement}

The authors declare no conflicts of interest to declare.

\section{Funding Sources}

The authors declare no financial involvement.

\section{Authors Contributions}

Dr. S.S.: review and write-up of content. Dr. B.S.: supervised, reviewed, and edited the content.

\section{References}

1 Remuzzi G, Benigni A, Remuzzi A. Mechanisms of progression and regression of renal lesions of chronic nephropathies and diabetes. J Clin Invest. 2006;116:288-96.

2 Snyder S, Pendergraph B. Detection and evaluation of chronic kidney disease. Am Fam Physician. 2005;72:1723-32.

3 Diamantis A, Magiorkinis E, Androutsos G. Proteinuria: from ancient observation to 19th century scientific study. J Urol. 2008;180(6): 2330.

4 Diamandopoulos A, Goudas P, Oreopoulos D. Thirty-six hippocratic aphorisms of nephrologic interest. 2009;54(1):143-53.

5 Cattran DC. Historical aspects of proteinuria. Adv Chronic Kidney Dis. 2011;18(4):224.

6 Levey AS, Gansevoort RT, Coresh J, Inker LA, Heerspink HL, Grams ME, et al. Change in albuminuria and gfr as end points for clinical trials in early stages of CKD: a scientific workshop sponsored by the national kidney foundation in collaboration with the US food and drug administration and european medicines agency. Am J Kidney Dis. 2020 Jan;75(1):84104.

7 Wheeler D, Stefansson B, Batiushin M, Bilchenko O, Cherney D, Chertow G, et al. The dapagliflozin and prevention of adverse outcomes in chronic kidney disease (DAPACKD) trial: baseline characteristics. Nephrol Dial Transplant. 1 October 2020;35(10): 1700-11.

8 Bailey MA, Shirley DG, Unwin RJ. Renal physiology. In Feehally J, Floege J, Tonelli M, Johnson RJ, editors. Comprehensive clinical nephrology. Philadelphia: Elsevier; 2019.

9 Brenner BM. Nephron adaptation to renal injury or ablation. Am J Physiol. 1985;249: F324-37.

10 López-Novoa JM, Rodríguez-Peña AB, Ortiz A, Martínez-Salgado C, López Hernández FJ. Etiopathology of chronic tubular, glomerular and renovascular nephropathies: clinical implications. J Transl Med. 2011;9(1):13.

11 Haraldsson J, Nystr" M, Deen WM. Properties of the glomerular barrier and mechanisms of proteinuria. Physiol Rev. 2008;88(2):45187.
12 Saritas T, Kuppe C, Moeller MJ. Progress and controversies in unraveling the glomerular filtration mechanism. Curr Opin Nephrol Hypertens. 2015;24:208-16.

13 Fissell WH, Miner JH. What is the glomerular ultrafiltration barrier? J Am Soc Nephrol. 2018 Sep;29(9):2262-4.

14 Scott RP, Quaggin SE. Review series: the cell biology of renal filtration. J Cell Biol. 2015 Apr 27;209(2):199-210.

15 Wickman L, Hodgin JB, Wang SQ, Afshinnia F, Kershaw D, Wiggins RC. Podocyte depletion in thin GBM and alport syndrome. PLoS One. 2016 May 18;11(5):e0155255.

16 Remuzzi G, Bertani T. Pathophysiology of progressive nephropathies. N Engl J Med. 1998;339:1448-56

17 Tuttle KR. Back to the future: glomerular hyperfiltration and the diabetic kidney. Diabetes. 2017;66(1):14-6.

18 Camici M. Renal glomerular permselectivity and vascular endothelium. Biomed Pharmacother. 2005;59(1-2):30-7.

19 Singh A, Satchell SC, Neal CR, McKenzie EA, Tooke JE, Mathieson PW. Glomerular endothelial glycocalyx constitutes a barrier to protein permeability. J Am Soc Nephrol. 2007; 18(11):2885-93.

20 Nielsen R, Christensen EI, Birn H. Megalin and cubilin in proximal tubule protein reabsorption: from experimental models to human disease. Kidney Int. 2016 Jan;89(1):5867.

21 Christensen EI, Birn H. Megalin and cubilin: synergistic endocytic receptors in renal proximal tubule. Am J Physiol Renal Physiol. 2001; 280:F562-73.

22 Haymann JP, Levraud JP, Bouet S, Kappes V, Hagège J, Nguyen G, et al. Characterization and localization of the neonatal $\mathrm{Fc}$ receptor in adult human kidney. J Am Soc Nephrol. 2000; 11:632-9.

23 Gudehithlu KP, Pegoraro AA, Dunea G, Arruda JA, Singh AK. Degradation of albumin by the renal proximal tubule cells and the subsequent fate of its fragments. Kidney Int. 2004;65:2113-22.

24 Park CH, Maack T. Albumin absorption and catabolism by isolated perfused proximal convoluted tubules of the rabbit. J Clin Invest. 1984;73:767-77.
25 Tanner SM, Sturm AC, Baack EC, Liyanarachchi S, de la Chapelle A. Inherited cobalamin malabsorption. Mutations in three genes reveal functional and ethnic patterns. Orphanet J Rare Dis. 2012 Aug;7:56.

26 Tryggvason K, Pettersson E. Causes and consequences of proteinuria: the kidney filtration barrier and progressive renal failure. J Intern Med. 2003;254:216-24.

27 Carrero JJ, Grams ME, Sang Y, Ärnlöv J, Gasparini A, Matsushita K, et al. Albuminuria changes are associated with subsequent risk of end-stage renal disease and mortality. Kidney Int. 2017 Jan;91(1):244-51.

28 Ruggenenti P, Schieppati A, Remuzzi G. Progression, remission, regression of chronic renal diseases. Lancet. 2001;357:1601-8.

29 Ruggenenti P, Perna A, Remuzzi G; GISEN Group Investigators. Retarding progression of chronic renal disease: the neglected issue of residual proteinuria. Kidney Int. 2003 Jun; 63(6):2254-61.

30 Liu D, Wen Y, Tang TT, Lv LL, Tang RN, Liu $\mathrm{H}$, et al. Megalin/cubulin-lysosome-mediated albumin reabsorption is involved in the tubular cell activation of NLRP3 inflammasome and tubulointerstitial inflammation. J Biol Chem. 2015 Jul 17;290(29):18018-28.

31 Jia Y, Zheng Z, Xue M, Zhang S, Hu F, Li Y, et al. Extracellular vesicles from albumin-induced tubular epithelial cells promote the M1 macrophage phenotype by targeting klotho. Mol Ther. 2019 Aug 7;27(8):1452-66.

32 Kamijo A, Kimura K, Sugaya T, Yamanouchi M, Hase H, Kaneko T, et al. Urinary free fatty acids bound to albumin aggravate tubulointerstitial damage. Kidney Int. 2002;62:162837.

33 Böttinger EP. TGF-beta in renal injury and disease. Semin Nephrol. 2007;27:309-20.

34 Fernandez-Fernandez B, Izquierdo MC, Valiño-Rivas L, Nastou D, Sanz AB, Ortiz A, et al. Albumin downregulates Klotho in tubular cells. Nephrol Dial Transplant. 2018 Oct 1; 33(10):1712-22.

35 Delitsikou V, Jarad G, Rajaram RD, Ino F, Rutkowski JM, Chen CD, et al. Klotho regulation by albuminuria is dependent on ATF3 and endoplasmic reticulum stress. FASEB J. 2020 Feb;34(2):2087-104. 
36 Oshima M, Neuen BL, Li J, Perkovic V, Charytan DM, de Zeeuw D, et al. Early change in albuminuria with canagliflozin predicts kidney and cardiovascular outcomes: a post hoc analysis from the credence trial. J Am Soc Nephrol. 2020 Dec;31(12):2925-36.

37 Sheng L, Zhuang S. New insights in to the role and mechanism of partial epithelial-mesenchymal transition in kidney fibrosis. Front Physiol. 2020;11:569322.

38 Liu Y. Epithelial to mesenchymal transition in renal fibrogenesis: pathologic significance, molecular mechanism, and therapeutic intervention. J Am Soc Nephrol. 2004;15:1-12.

39 Eddy AA. Molecular insights into renal interstitial fibrosis. J Am Soc Nephrol. 1996;7: 2495-508.

40 Abbate M, Zoja C, Remuzzi G. How does proteinuria cause progressive renal damage? J Am Soc Nephrol. 2006;17:2974-84.

41 Burlaka I, Nilsson LM, Scott L, Holtbäck U, Eklöf AC, Fogo AB, et al. Prevention of apoptosis averts glomerular tubular disconnection and podocyte loss in proteinuric kidney disease. Kidney Int. 2016 Jul;90(1):135-48.

42 Wohlfarth V, Drumm K, Mildenberger S, Freudinger R, Gekle M. Protein uptake disturbs collagen homeostasis in proximal tubule-derived cells. Kidney Int Suppl. 2003;84: S103-9.

43 Sanchez-Niño MD, Benito-Martin A, Gonçalves S, Sanz AB, Ucero AC, Izquierdo MC, et al. TNF superfamily: a growing saga of kidney injury modulators. Mediators Inflamm. 2010;2010:182958.

44 Sheng L, Zhuang S. New insights in to the role and mechanism of partial epithelial-mesenchymal transition in kidney fibrosis. Front Physiol. 2020 Sep 15;11:569322.

45 Wu KL, Khan S, Lakhe-Reddy S, Wang L, Ja$\operatorname{rad}$ G, Miller RT, et al. Renal tubular epithelial cell apoptosis is associated with caspase cleavage of the NHE1 Na+/H+ exchanger. Am J Physiol Renal Physiol. 2003 Apr;284(4): F829-39.

46 Tan RJ, Li Y, Rush BM, Cerqueira DM, Zhou $\mathrm{D}, \mathrm{Fu} \mathrm{H}$, et al. Tubular injury triggers podocyte dysfunction by $\beta$-catenin-driven release of MMP-7. JCI Insight. 2019 Dec 19;4(24): e122399.

47 Kidney Disease: Improving Global Outcomes (KDIGO) Diabetes Work Group. KDIGO 2020 clinical practice guideline for diabetes management in chronic kidney disease. Kidney Int. 2020;98(4S):S1-S115.

48 Heerspink HJL, Greene T, Tighiouart H, Gansevoort RT, Coresh J, Simon AL, et al. Chronic kidney disease epidemiology collaboration. change in albuminuria as a surrogate endpoint for progression of kidney disease: a meta-analysis of treatment effects in randomised clinical trials. Lancet Diabetes Endocrinol. 2019 Feb;7(2):128-39.
49 Coresh J, Heerspink HJL, Sang Y, Matsushita $\mathrm{K}$, Arnlov J, Astor BC, et al. Change in albuminuria and subsequent risk of end-stage kidney disease: an individual participant-level consortium meta-analysis of observational studies. Lancet Diabetes Endocrinol. 2019 Feb;7(2):115-27.

50 Parving $\mathrm{HH}$, Brenner BM, McMurray JJ, de Zeeuw D, Haffner SM, Solomon SD, et al. Altitude investigators. cardiorenal end points in a trial of aliskiren for type 2 diabetes. $\mathrm{N}$ Engl J Med. 2012 Dec 6;367(23):2204-13.

51 Heerspink HJL, Parving HH, Andress DL, Bakris G, Correa-Rotter R, Hou FF, et al Atrasentan and renal events in patients with type 2 diabetes and chronic kidney disease (SONAR): a double-blind, randomised, placebo-controlled trial. Lancet. 2019 May 11; 393(10184):1937-47.

52 Levey AS, Gansevoort RT, Coresh J, Inker LA, Heerspink HL, Grams ME, et al. Change in albuminuria and GFR as end points for clinical trials in early stages of CKD: a scientific workshop sponsored by the national kidney foundation in collaboration with the us food and drug administration and European medicines agency. Am J Kidney Dis. 2020 Jan; 75(1):84-104

53 Thompson A, Carroll K, Inker A, Floege J, Perkovic V, Boyer-Suavet S, et al. Proteinuria reduction as a surrogate end point in trials of IgA nephropathy. Clin J Am Soc Nephrol. 2019 Mar 7;14(3):469-81.LJA

54 Inker LA, Lambers-Heerspink H, Tighiouart H, Chaudhari J, Miao S, Diva U, et al. Association of treatment effects on early change in urine protein and treatment effects on GFR slope in IgA nephropathy: an individual participant meta-analysis. Am J Kidney Dis. 2021 Mar 25. S0272-6386(21):00502-3.

55 Eijkelkamp WB, Zhang Z, Remuzzi G, Parving $\mathrm{HH}$, Cooper ME, Keane WF, et al. Albuminuria is a target for renoprotective therapy independent from blood pressure in patients with type 2 diabetic nephropathy: Post hoc analysis from the reduction of endpoints in NIDDM with the angiotensin II antagonist losartan (RENAAL) trial. J Am Soc Nephrol. 2007; 18:1540-6.

56 Morelli E, Loon N, Meyer TW, Peters W, Myers BD. Effects of converting-enzyme inhibition on barrier function in diabetic glomerulopathy. Diabetes. 1990;39:76-82.

57 Nakamura Obata TJ, Kimura H, Ohno S, Yoshida Y, Kawaihi H, Shimizu F. Blocking angiotensin II ameliorates proteinuria and glomerular lesions in progressive mesangioproliferative glomerulonephritis. Kidney Int. 1999;55:877-89.

58 Fried LF, Emanuele N, Zhang JH, Brophy M, Conner TA, Duckworth W, et al. Combined angiotensin inhibition for the treatment of diabetic nephropathy. N Engl J Med. 2013 Nov 14:369(20): 1892-903.
59 The GISEN Group (Gruppo Italiano di Studi Epidemiologici in Nefrologia). Randomised placebo-controlled trial of effect of ramipril on decline in glomerular filtration rate and risk of terminal renal failure in proteinuric, non-diabetic nephropathy. The GISEN group (Gruppo Italiano di Studi Epidemiologici in Nefrologia). Lancet. 1997;349:1857-63.

60 Giatras I, Lau J, Levey AS. Effect of angiotensin-converting enzyme inhibitors on the progression of nondiabetic renal disease: a metaanalysis of randomized trials. Angiotensinconverting-enzyme inhibition and progressive renal disease study group. Ann Intern Med. 1997;127(5):337-45.

61 Ye H, Huo Z, Ye P, Xiao G, Zhang Z, Xie C, et al. Comparative proteinuria management of different angiotensin-converting enzyme inhibitors or angiotensin receptor blockers for normotensive patients with CKD: a Bayesian network meta-analysis. PeerJ. 2020;8:e8575.

62 Jafar TH, Schmid CH, Landa M, Giatras I, Toto R, Remuzzi G, et al. Angiotensin-converting enzyme inhibitors and progression of nondiabetic renal disease. A meta-analysis of patient-level data. Ann Intern Med. $2001 \mathrm{Jul}$ 17;135(2):73-87.

63 obe SW, Clase CM, Gao P, McQueen M, Grosshennig A, Wang X, et al. Cardiovascular and renal outcomes with telmisartan, ramipril, or both in people at high renal risk: results from the ontarget and transcend studies. Circulation. 2011 Mar 15;123(10):1098107.

64 Yusuf S, Teo KK, Pogue J, Dyal L, Copland I, Schumacher $\mathrm{H}$, et al. Telmisartan, ramipril, or both in patients at high risk for vascular events. N Engl J Med. 2008;358(15):1547-59.

65 The Telmisartan Randomised AssessmeNt Study in ACE iNtolerant subjects with cardiovascular Disease (TRANSCEND) Investigators. Effects of the angiotensin-receptor blocker telmisartan on cardiovascular events in high-risk patients intolerant to angiotensin-converting enzyme inhibitors: a randomised controlled trial. Lancet. Published on-line 29 August 2008.

66 Parving HH, Brenner BM, McMurray JJ, de Zeeuw D, Haffner SM, Solomon SD, et al Cardiorenal end points in a trial of aliskiren for type 2 diabetes. N Engl J Med. 2012 Dec 6; 367(23):2204-13.

67 Mishima E, Haruna Y, Arima H. Renin-angiotensin system inhibitors in hypertensive adults with non-diabetic CKD with or without proteinuria: a systematic review and meta-analysis of randomized trials. Hypertens Res. 2019;42:469-82.

68 Improving Global Outcomes (KDIGO) Blood Pressure Work Group. KDIGO clinical practice guideline for the management of blood pressure in chronic kidney disease. Kidney inter., Suppl.. 2012;2:337-414. 
69 Wanner C, Inzucchi SE, Lachin JM, Fitchett D, von Eynatten M, Mattheus M, et al. Empagliflozin and progression of kidney disease in type 2 diabetes. N Engl J Med. 2016;375:32334.

70 Toto RD. SGLT-2 inhibition: a potential new treatment for diabetic kidney disease? Nephron. 2017;137(1):64-7.

71 Zannad F, Ferreira JP, Pocock SJ, Pocock SJ, Anker SD, Butler J, et al. SGLT2 inhibitors in patients with heart failure with reduced ejection fraction: a meta-analysis of the EMPEROR-Reduced and DAPA-HF trial. Lancet. 2020;396(10254):819.

72 Perkovic V, de Zeeuw D, Mahaffey KW, Fulcher G, Erondu N, Shaw W, et al. Canagliflozin and renal outcomes in type 2 diabetes: results from the CANVAS Program randomised clinical trials. Lancet Diabetes Endocrinol. 2018;6:691-704.

73 Jardine MJ, Mahaffey KW, Neal B, Neal B, Agarwal R, Bakris GL, et al. The canagliflozin and renal endpoints in diabetes with established nephropathy clinical evaluation (CREDENCE) study rationale, design, and baseline characteristics. Am J Nephrol. 2018;46:46272.

74 Cherney DZI, Dekkers CCJ, Barbour SJ, Cattran D, Abdul Gafor AH, Greasley PJ, et al. Effects of the SGLT2 inhibitor dapagliflozin on proteinuria in non-diabetic patients with chronic kidney disease (DIAMOND): a randomised, double-blind, crossover trial. Lancet Diabetes Endocrinol. 2020;8(8):582-93.

75 McGuire DK, Shih WJ, Cosentino F, Charbonnel B, Cherney DZI, Dagogo-Jack S, et al. Association of SGLT2 inhibitors with cardiovascular and kidney outcomes in patients with type 2 diabetes: a meta-analysis. JAMA Cardiol. 2021 Feb 1;6(2):148-58.

76 Cassis P, Locatelli M, Cerullo D, Corna D, Buelli S, Zanchi C, et al. SGLT2 inhibitor dapagliflozin limits podocyte damage in proteinuric nondiabetic nephropathy. JCI Insight. 2018;3(15):e98720.
77 Škrtić M, Cherney DZ. Sodium-glucose cotransporter-2 inhibition and the potential for renal protection in diabetic nephropathy. Curr Opin Nephrol Hypertens. 2015;24(1): 96-103.

$78 \mathrm{Ma}$ Q, Steiger S, Anders H-J. Sodium glucose transporter-2 inhibition has no renoprotective effects on non-diabetic chronic kidney disease. Physiol Rep. 2017;5:e13228.

79 Vallon V, Gerasimova M, Rose MA, Masuda T, Satriano J, Mayoux E, et al. SGLT2 inhibitor empagliflozin reduces renal growth and albuminuria in proportion to hyperglycemia and prevents glomerular hyperfiltration in diabetic Akita mice. Am J Physiol Renal Physiol. 2014;306(2):F194-204.

80 Perico L, Conti S, Benigni A, Remuzzi G. Podocyte-actin dynamics in health and disease. Nat Rev Nephrol. 2016;12(11):692-710.

81 Li J, Neal B, Perkovic V, de Zeeuw D, Neuen BL, Arnott C, et al. Mediators of the effects of canagliflozin on kidney protection in patients with type 2 diabetes. Kidney Int. 2020 Sep; 98(3):769-77.

82 Mosenzon O, Wiviott SD, Cahn A, Rozenberg A, Yanuv I, Goodrich EL, et al. Effects of dapagliflozin on development and progression of kidney disease in patients with type 2 diabetes: an analysis from the DECLARETIMI 58 randomised trial. Lancet Diabetes Endocrinol. 2019 Aug;7(8):606-17.

83 Neuen BL, Ohkuma T, Neal B, Matthews DR, de Zeeuw D, Mahaffey KW, et al. Effect of canagliflozin on renal and cardiovascular outcomes across different levels of albuminuria: data from the CANVAS program. J Am Soc Nephrol. 2019;30(11):2229-42.

84 Zhang Y, Thai K, Kepecs DM, Gilbert RE. Sodium-glucose linked cotransporter-2 inhibition does not attenuate disease progression in the rat remnant kidney model of chronic kidney disease. PLoS One. 2016;11(1):e0144640.
85 Kelly MS, Lewis J, Huntsberry AM, Dea L, Portillo I. Efficacy and renal outcomes of SGLT2 inhibitors in patients with type 2 diabetes and chronic kidney disease. Postgrad Med. 2019 Jan;131(1):31-42.

86 Heerspink HJL, Parving HH, Andress DL, Bakris G, Correa-Rotter R, Hou FF, et al. Atrasentan and renal events in patients with type 2 diabetes and chronic kidney disease (SONAR): a double-blind, randomised, placebo-controlled trial. Lancet. 2019 May 11; 393(10184):1937-47.

87 Mann JF, Green D, Jamerson K, Ruilope LM, Kuranoff SJ, Littke T, et al. Avosentan for overt diabetic nephropathy. J Am Soc Nephrol. 2011;21:527-35.

88 Bakris GL, Agarwal R, Anker SD, Pitt B, Ruilope LM, Rossing P, et al. Effect of finerenone on chronic kidney disease outcomes in type 2 diabetes. N Engl J Med. 2020;383(23): 2219-29.

89 De Zeeuw D, Akizawa T, Agarwal R, Audhya P, Bakris G, Chin M, et al. Bardoxolone methyl Evaluation in patients with chronic kidney disease and type 2 diabetes: the occurrence of renal events (BEACON): rationale and trial design. Am J Nephrol. 2013;37:212-22.

90 Chin M, Bakris GL, Block GA, Chertow GM, Goldsberry A, Inker L, et al. Bardoxolone methyl improves kidney function in patients with chronic kidney disease stage 4 and type 2 diabetes: post-hoc analyses from bardoxolone methyl evaluation in patients with chronic kidney disease and type 2 diabetes study. Am J Nephrol. 2018;47:40-7.P

91 James VJ, Berg P, Sheetz M, Duffin K, Shen T, Moser B, et al. Anti-TGF- $\beta 1$ antibody therapy in patients with diabetic nephropathy. J Am Soc Nephrol. 2017;28(3):953-62.

92 Sharma K, Ix JH, Mathew AV, Cho M, Pflueger A, Dunn SR, et al. Pirfenidone for diabetic nephropathy. J Am Soc Nephrol. 2011 Jun;22(6):1144-51. 